\title{
Sufficient conditions for the existence of some nonoscillatory solutions of third-order nonlinear differential equations
}

\section{IVAN MOJSEj and AlenA TARTAL'OvÁ}

\section{ABSTRACT.}

The aim of this paper is to study the asymptotic behavior of solutions of nonlinear differential equations of the third-order with quasiderivatives. In particular, we state the sufficient conditions ensuring the existence of some nonoscillatory solutions with a specified asymptotic property as $t$ tends to infinity. The basic tool used in proving our results is the classical Banach contraction mapping principle.

Acknowledgment. The first author was supported by the grant 2/0035/11 of the Grant Agency of Slovak Republic (VEGA) and by the grant VVGS 45/10-11 and the second author by the grant 1/0724/08 of the Grant Agency of Slovak Republic (VEGA).

\section{REFERENCES}

[1] Agarwal, R. P., Bohner, M. and Li, W. T., Nonoscillation and oscillation: Theory for functional differential equations, Pure Appl. Math. 267, Dekker, New York, 2004

[2] Aktas, M. F., Tiryaki, A. and Zafer, A., Integral criteria for oscillation of third order nonlinear differential equations, Nonlinear Anal. 71 (2009), No. $12,1496-1502$

[3] Bartušek, M., On oscillatory solutions of third order differential equation with quasiderivatives, Electron. J. Differ. Equ. Conf. 03 (1999), 1-11

[4] Berinde, V., Iterative Approximation of Fixed Points, Lectures Notes in Mathematics 1912, Springer Verlag, Berlin Heidelberg New York, 2007

[5] Cecchi, M., Došlá, Z. and Marini, M., On nonlinear oscillations for equations associated to disconjugate operators, Nonlinear Anal. 30 (1997), No. 3 , 1583-1594

[6] Cecchi, M., Došlá, Z., and Marini, M., An equivalence theorem on properties A, B for third order differential equations, Ann. Mat. Pura Appl. (IV), CLXXIII (1997), 373-389

[7] Cecchi, M., Marini, M. and Villari, G., On some classes of continuable solutions of a nonlinear differential equation, J. Differential Equations 118 (1995), 403-419

[8] Dobritoiu, M., System of integral equations with modified argument, Carpathian J. Math. 24 (2008), No. 2, 26-36

[9] Džurina, J., Comparison theorems for functional differential equations, EDIS-Žilina University Publisher, Žilina, 2002

[10] Džurina, J. and Kotorová, R., Properties of the third order trinomial differential equations with delay argument, Nonlinear Anal. 71 (2009), No. 5-6, 1995-2002

[11] Kiguradze, I., On asymptotic properties of solutions of third order linear differential equations with deviating arguments, Arch. Math. (Brno) 30 (1994), $59-72$

[12] Knežo, D. and Šoltés, V., Existence and properties of nonoscillatory solutions of third order differential equation, Fasc. Math. 25 (1995), 63-74

[13] Ladde, G. S., Lakshmikantham, V. and Zhang, B.G., Oscillation theory of differential equations with deviating arguments, Pure Appl. Math. 110, Dekker, New York, 1987

[14] Liu, Y., Existence of positive periodic solutions of functional difference equations with sign-changing terms, Carpathian J. Math. 26 (2010), No. 1, 77-85

[15] Mihalíková, B. and Kostiková, E., Boundedness and oscillation of third order neutral differential equations, Tatra Mt. Math. Publ. 43 (2009), 137-144

[16] Mojsej, I., Asymptotic properties of solutions of third-order nonlinear differential equations with deviating argument, Nonlinear Anal. 68 (2008), No. $11,3581-3591$

[17] Mojsej, I. and Ohriska, J., Comparison theorems for noncanonical third order nonlinear differential equations, Cent. Eur. J. Math. 5 (2007), No. 1, $154-163$

[18] Mojsej, I. and Tartalová, A., On bounded nonoscillatory solutions of third-order nonlinear differential equations, Cent. Eur. J. Math. 7 (2009), No. 4, 717-724

[19] Muresan, V., Step method for a functional-differential equation in Banach space, Carpathian J. Math. 24 (2008), No. 3, 363-369

[20] Parhi, N. and Padhi, S., Asymptotic behaviour of a class of third order delay differential equations, Math. Slovaca 50 (2000), No. 3, 315-333

[21] Philos, Ch. G. and Sficas, Y. G., Oscillatory and asymptotic behavior of second and third order retarded differential equations, Czechoslovak Math. J. 32 (1982), No. 107, 169-182

[22] Šoltés, V., Property (A) of the n-th order differential equations with deviating argument, Arch. Math. (Brno) 31 (1995), 59-63

INSTITUTE OF MATHEMATICS

FACULTY OF SCIENCE, P. J. ŠAFÁRIK UNIVERSITY

JESENNÁ 5, 04001 KošICE, Slovak Republic

E-mail address: ivan.mojsej@upjs.sk

DEPARTMENT OF APPLIED MATHEMATICS AND BUSINESS INFORMATICS

FACULTY OF ECONOMICS, TECHNICAL UNIVERSITY

Nemcovej 32, 04001 Košice, SlovaK Republic

E-mail address: a lena.tarta lova@tuke.sk 